\title{
Bubble and Heat Transfer Phenomena in Viscous Slurry Bubble Column
}

\author{
Hyo Sik Kim¹, Jin Ho Kim', Chan Gi Lee1, Suk Hwan Kang1*, Kwang Jae Woo², Ho Jin Jung2, \\ Dong Wook Kim ${ }^{3 *}$ \\ ${ }^{1}$ Plant Engineering Center, Institute for Advanced Engineering (IAE), Gyongki-do, Korea \\ ${ }^{2}$ DAEWOONG E \& S, Daejeon, Korea \\ ${ }^{3}$ Department of Environmental Engineering, Kongju National University, Cheonan, Korea \\ Email: ${ }^{*}$ shkang@iae.re.kr, ${ }^{*}$ dwkim@kongju.ac.kr
}

Received 18 July 2014; revised 18 August 2014; accepted 28 August 2014

Copyright (C) 2014 by authors and Scientific Research Publishing Inc.

This work is licensed under the Creative Commons Attribution International License (CC BY).

http://creativecommons.org/licenses/by/4.0/

c) (7) Open Access

\begin{abstract}
Heat transfer and bubble phenomena were investigated by adopting the drift flux model in a viscous slurry bubble column reactor (SBCR), having a diameter of $0.0508 \mathrm{~m}$ (ID) and height $1.5 \mathrm{~m}$. The effects of superficial gas velocity $(0.002-0.164 \mathrm{~m} / \mathrm{s})$, solid concentration $(0-20$ wt $\%)$ and liquid viscosity (paraffin oil; $16.9 \mathrm{mPa} \cdot \mathrm{s}$ and squalane; $25.9 \mathrm{mPa} \cdot \mathrm{s}$ ) on the gas holdup and heat transfer characteristics were examined. It was observed that the gas holdup increased with increasing superficial gas velocity $\left(U_{G}\right)$, but decreased with increasing solid concentration $\left(S_{C}\right)$ or slurry viscosity. The degree of non-uniformity in a SBCR could be determined by the modified drift flux model at the heterogeneous flow regime. The local heat transfer coefficient (h) between the immersed heater and the bed decreased with increasing liquid viscosity and $S_{C}$, but it increased with increasing $U_{G}$. The modified Nusselt number including the gas holdup and local heat transfer coefficient was well correlated in terms of dimensionless groups such as Reynolds and Prandtl numbers.
\end{abstract}

\section{Keywords}

Gas Holdup, Slurry Bubble Column, Heat Transfer, Drift Flux Model

\section{Introduction}

Slurry bubble column reactors (SBCR) which have many advantages relative to other types of reactors can be widely used in industry for syngas conversion reactions such as Fischer-Tropsch synthesis and methanol synthe-

${ }^{*}$ Corresponding authors.

How to cite this paper: Kim, H.S., Kim, J.H., Lee, C.G., Kang, S.H., Woo, K.J., Jung, H.J. and Kim, D.W. (2014) Bubble and Heat Transfer Phenomena in Viscous Slurry Bubble Column. Advances in Chemical Engineering and Science, 4, 417-429. 
sis, heavy oil upgrading, bio-conversion processes, and biological and dissolved air flotation (DAF) processes in sewage and wastewater treatments [1] [2]. The advantages of slurry bubble column reactor are including that it could be operated at nearly isothermal operation and flexibility to use small solid particles, which consequently results in good productivity, good interface contact, low pressure drop, and low construction and operation costs. Because of those inherent merits, some investigators have recently studied on the hydrodynamics and transport phenomena in SBCR aiming at commercial design or scale-up as well as for the separation between liquid products and solid catalysts using the hydrocyclone or modified geometric devices [3].

For the SBCR design, the understanding on the mixing among gas, liquid and particles, individual phase holdup and heat and mass transfer in the column are certainly essential. In addition, the flow behavior of gas phase is known to act a pivotal role in determining the heat transfer coefficient, since the gas bubbles, which exist as a dispersed phase, flow stochastically and randomly in the viscous slurry medium which is composed of solvent with particles [4]-[6]. Gas holdup is directly affected by gas velocity and particle concentration and is generally found to decrease with an increase of particle concentration in a SBCR [7]-[9]. With the addition of particles in bubble column, there will be an increase in the apparent viscosity of suspension [10] [11]. However, the characteristics of the heat transfer in the column have been estimated mainly by local heat transfer coefficients. In general, the local heat transfer coefficient has significant influence on bubbles which passed the surface of the probe. These bubbles could split with addition of particles in a column.

In the present study, hydrodynamic characteristics of a slurry bubble column are analyzed by means of phase holdup under different conditions and by the drift flux model determining the rising velocity of single bubble. In addition, the heat transfer phenomena are examined with change in operation variables such as gas velocity, liquid and solid concentration in the slurry phase. On the basis of the results obtained, a good correlation has been developed among the dimensionless groups which have relationships with gas holdup and heat transfer coefficient useful for design of practical SBCR.

\section{The Drift Flux Model}

The drift flux $\left(j_{g m}\right)$ is defined by Wallis [12] as the volumetric flux of gas relative to a surface moving at a velocity equal to the total of the superficial gas and liquid velocity. For the SBCR, the modified local drift flux is calculated by

$$
J_{g m}=U_{G}\left(1-\varepsilon_{G}\right)=V s\left(1-\varepsilon_{G}\right) \varepsilon_{G}
$$

where, $J_{g m}$ and $V s$ are the drift flux velocity and the local slip velocity, respectively. A plot of drift flux verses $\varepsilon_{G}$ can be used to classify the flow regimes [13]. The change of slope clearly indicates the transition of flow regime. These flow regimes depend on the liquid circulation and current type, solid properties such as size and density, and reactor diameter, etc.

In addition, the drift flux model modified by Zuber and Findlay [14] is widely recommended for modeling gas holdup in bubble columns [15] [16]. It accounts for the effects of radial non-uniformity of the superficial gas velocity and gas holdup, and the effect of interstitial gas velocity $\left(U_{G} / \varepsilon_{G}\right)$ between the two phases of gas and liquid. Zuber and Findlay [14] derived that:

$$
\frac{U_{G}}{\varepsilon_{G}}=K\left(U_{G}+U_{L}\right)+\bar{V}_{g m}
$$

$K$ is called the distribution parameter and is a constant related to the degree of non-uniformity in the bubble column (for a uniform radial gas holdup profile, $K=1$; for a center-peaked radial gas holdup profile, $K>1$ [17]); and

$$
\bar{V}_{g m}=\frac{J_{g m}}{\varepsilon_{G}}
$$

is called the weighted mean drift velocity and indicates the effect of the local relative velocity. Also, the bubble column is operated in batch mode; hence, the superficial liquid velocity is zero.

\section{Experiments}

Experiments were carried out in an acryl column of $0.0508 \mathrm{~m}$ in diameter and $1.5 \mathrm{~m}$ in height (Figure 1). Oil- 


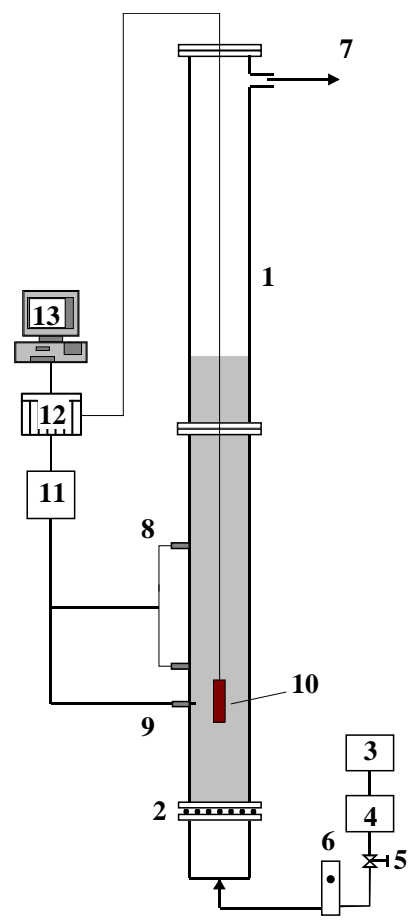

Figure 1. Experimental apparatus. 1: Main column; 2: Distributor; 3: Compressor; 4: Filter and regulator; 5: Valve; 6: Flowmeter; 7: Vent; 8: Pressure transducer; 9: Thermocouple; 10: Cartridge heater; 11: Low-pass filter; 12: A/D Convertor; 13: Computer.

free compressed air was fed to the column through a pressure regulator, filter and a calibrated flow meter. It was admitted to the column through a perforated plate distributor. The distributor contained 30 holes with triangular pitches; the diameter of each hole was $0.5 \mathrm{~mm}$.

The dynamic pressure fluctuations for the measuring gas holdup was measured at the center of the bed through the pressure taps that were mounted flush with the wall of the column between 0.3 and $0.4 \mathrm{~m}$ from the distributor. Pressure fluctuations were measured and detected by sensitive differential pressure transducer (Validyne, Model P24D) attached to the pressure probes. The voltage-time signals, corresponding to the pressuretime signals, were sampled at a rate of 300/s and stored in the data acquisition system (Data Precision-Model, DT2805). The total acquisition time was $10 \mathrm{~s}$ having 3000 data points. The gas holdup is determined from

$$
\begin{aligned}
& \varepsilon_{G}+\varepsilon_{S L}=1 \\
& \varepsilon_{G}=1-\frac{\Delta P}{\left[\rho_{L}+\varepsilon_{S}\left(\rho_{S}-\rho_{L}\right)\right] g L}
\end{aligned}
$$

where, the solid volume fraction within the bubble column, $\varepsilon_{S}$, is determined from the known slurry volume and the solid weight percent [18]. Experiments performed in the range of $0.002-0.164 \mathrm{~m} / \mathrm{s}$ (superficial gas velocity) and 0 - $26 \mathrm{wt} \%$ (solid concentration), respectively. Paraffin oil $\left(880 \mathrm{~kg} / \mathrm{m}^{3}, 16.9 \mathrm{mPa} \cdot \mathrm{s}\right)$ and squalane $\left(800 \mathrm{~kg} / \mathrm{m}^{3}\right.$, $25.9 \mathrm{mPa} \cdot \mathrm{s}$ ) were used as liquid phase to make the slurry phase. Catapal B (boehmite) with an average diameter of $60 \mu \mathrm{m}$ and a density of $2074 \mathrm{~kg} / \mathrm{m}^{3}$ was used as solid particle to comprise the slurry phase.

The local heat transfer coefficients were determined by Equation (4) from the knowledge of amount of heat supply and temperature difference between the heater surface $\left(T_{s}\right)$ and the bed $\left(T_{b}\right)$ [19] [20].

$$
h=\frac{Q}{A\left(T_{s}-T_{b}\right)}
$$

The heat supply $(Q)$ was obtained from the DC power supplier, and it was verified by means of the energy balance in the column. 


\section{Results and Discussion}

In the SBCR, the gas holdup is one of the most important parameters used to describe its performance. The behavior of the gas holdup has been attributed to many different factors, including the physical properties of gas/ liquid/solid phase, column geometry, gas distributor design, and the operating variables such as pressure, gas velocity, temperature, and solid concentration. In particular, the gas velocities among these variables have large effect on the flow regimes; homogeneous, heterogeneous and slug flow and transition regime for air-water (gasliquid bubble column) system [21]. Transition regime as a boundary layer of each flow can shift depending on the experimental setup and system used. Therefore, some investigators proposed that the operation of SBCR be carried out in the homogeneous flow regime of below $4 \mathrm{~cm} / \mathrm{s}$.

Figure 2 illustrates the effect of superficial gas velocity on the gas holdup for squalane and paraffin oil in a SBCR. In this figure, the gas holdup has shown a positive effect of the superficial gas velocity. The dependence of the gas holdup on the superficial gas velocity can best be defined by the following power-law expression as $\varepsilon_{G}=U_{G}^{n}$ [7]. Initially, the gas holdup seems to increase sharply and almost linearly with the superficial gas velocity in the homogeneous flow regime [7] [22]. The increase in the gas holdup then reaches a maximum where the transition from homogeneous to heterogeneous flow regime occurs, and consequently a more non-linear increase with the superficial gas velocity beyond that point can be observed, as shown in Figure 2.

In the present investigation it was observed that the solid holdup in homogeneous flow regime decreased slowly with the superficial gas velocity in dilute slurry phase, but it decreased rapidly in slurry phase of high solid concentration. On the other hand, the solid holdup in heterogeneous flow regime has not much of an effect on the superficial gas velocity. Physical properties of the liquid can have a major effect on the gas holdup in a SBCR. In this work, we used squalane and paraffin as liquid phases. Viscosity of squalane is higher than that of paraffin oil. A comparison of the gas holdups of squalane and paraffin oil, reveals that the gas holdup decreases

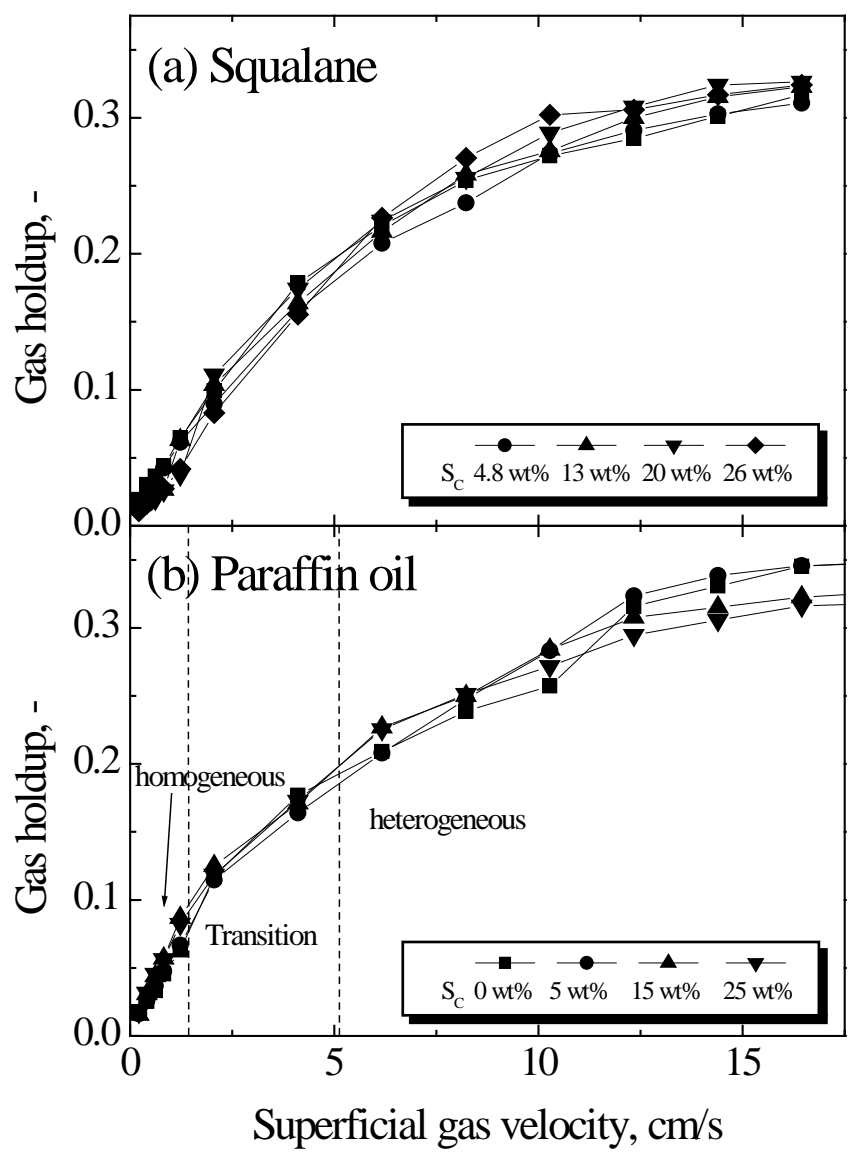

Figure 2. Effects of superficial gas velocity for the squalane and the paraffin oil on the gas holdup in a slurry bubble column reactor. 
with increasing liquid viscosity since the high liquid viscosity promotes bubble coalescence [23]. Large gas bubbles which are formed by the coalescence of small bubbles have the faster rising velocity, and this result causes the decrease of the gas holdup as well as the transition from homogenous to churn turbulent flow regime.

The effect of solid concentration (Sc) on the gas holdup is shown in Figure 3. The gas holdup decreases gradually or dose not change considerably, with increasing solid concentration in a SBCR. This behavior is related to the fact that the increase of solid concentration can lead to the increase of slurry viscosity which promotes the formation of larger gas bubbles. Like this, an increase of bubble size increases the bubble rising velocity and decreases the residence time of the bubble in a SBCR. Furthermore, if gas velocity is maintained at constant level, the gas momentum per unit mass of slurry would decrease with increasing solid concentration and thus, the total gas holdup is expected to decrease with increasing solid concentration [4]. In addition, the slurry viscosity with solid concentration tends to decrease gradually by the increase of liquid viscosity, since the interfacial tension of bubbles has increased and the boundary layer thickness of the bubbles has increased [6].

However, some investigators have studied various methods to analyze the bubbling behavior in the bubble column. A fractal approach was proposed to describe the behavior of pressure fluctuations to distinguish between the homogeneous and heterogeneous regime [20] and the multi-resolution analysis was used to study the local structure and regime transition in a gas-liquid bubble column [24]. In addition, other workers adopted the Kolmogorov entropy or Correlation Dimensions to quantify the chaos dynamics in bubble columns [25] [26]. Recently, several investigators have used the drift flux model for predicting regime transition and for analyzing hydrodynamics in the column. Therefore, in this work, we used the modified drift model to analyze the bubbling behavior in the SBCR. A plot of volumetric flux of gas phase versus fractional gas holdup adopting the modified

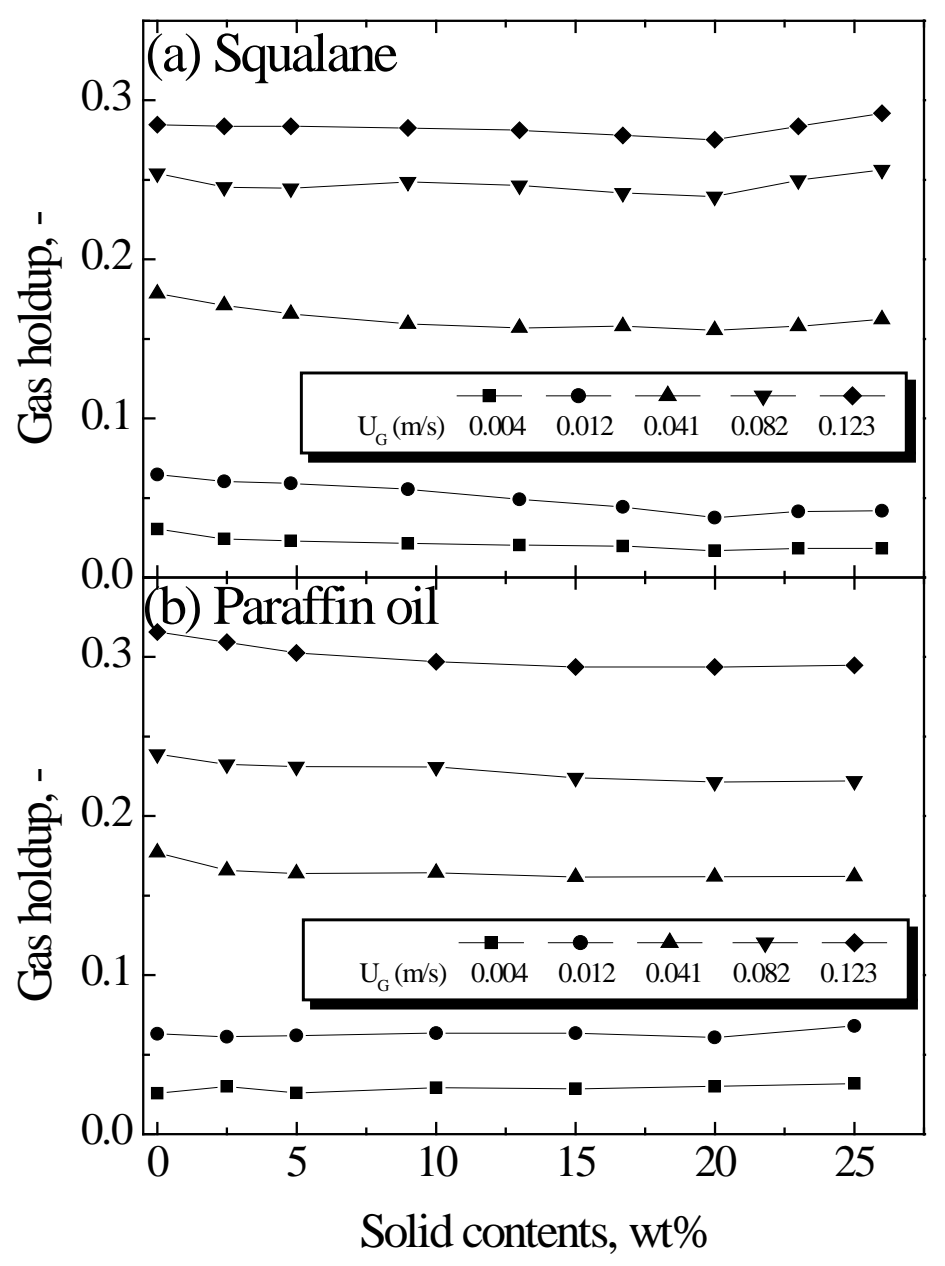

Figure 3. Effects of solid concentration for the squalane and the paraffin oil on the gas holdup in a slurry bubble column reactor. 
drift model is illustrated in Figure 4. The profiles are similar to the result on the curves of the drift flux reported by Thorat \& Joshi in the bubble column [13]. Initially, homogeneous flow regime of the low gas holdup attains the heterogeneous flow regime through transition points with increasing gas holdup. Since the drift flux in heterogeneous flow regime has increased rapidly with $\varepsilon_{G}$, the distinction between transition regime and heterogeneous flow regime can be determined easily. However, the transition points changed with solid concentration, thus the studies on the change of transition regime are necessary.

Figure 5 adopted the drift flux model proposed by Zuber and Findlay [14] using the results on the flow regimes classified in Figure 4. The change of interstitial gas velocity in homogeneous flow is shown in Figure 5(a). Interstitial gas velocity with superficial gas velocity or with solid concentration has not followed any tendency. At the relatively higher solid concentration, although the superficial gas velocity increases, interstitial gas velocity decreases because of the gas holdup than the amount of gas increased by the formation of the large bubble. On the other hand, the interstitial gas velocity in heterogeneous flow [Figure 5(b)] varied linearly with the superficial gas velocity. Moreover, the slope $(\mathrm{K})$ indicative of the degree of non-uniformity is calculated as $2.21(S c=0), 2.30$ ( $S c=4.8 \mathrm{wt} \%), 2.59(S c=13 \mathrm{wt} \%)$ and 2.86 ( $S c=20 \mathrm{wt} \%)$, respectively. Like this, the nonuniformity of bubble holdup can be detected in the churn turbulent flow regime as heterogeneous flow. As can be seen in Figure 5, the results of this study fitted well to Equation (2), since the plots are essentially linear in each case. Note that the value of $\mathrm{K}$ increases with increasing solid concentration. This implies that the degree of non-uniformity of bubbling phenomena increases and bubble rising velocity increases, with solid concentration in heterogeneous flow.

However, the correlation on the holdup for the modeling, design and scale-up of SBCR was required certainly. But, as can be seen Table 1, some investigators reported only in a slurry bubble column. In this work, the gas holdup was correlated well as a function of the operation variables, as represented by Equation (5).

$$
\frac{\varepsilon_{G}}{1-\varepsilon_{G}}=0.0575 S C^{-0.0082} U_{G}^{0.8168} \mu_{L}^{-0.2734} \rho_{L}^{0.1783}
$$

where, the correlation coefficient of Equation (5) is 0.97. The Equation (5) cover the following range of variables: $0 \mathrm{wt} \% \leq S c \leq 25 \mathrm{wt} \%, 2.1 \times 10^{-3} \mathrm{~m} / \mathrm{s} \leq U_{G} \leq 2.057 \times 10^{-1} \mathrm{~m} / \mathrm{s}, 1.69 \times 10^{-4} \mathrm{~kg} / \mathrm{ms} \leq \mu_{L} \leq 2.59 \times 10^{-4}$ $\mathrm{kg} / \mathrm{ms}$ and $800 \mathrm{~kg} / \mathrm{m}^{3} \leq \mu_{L} \leq 875 \mathrm{~kg} / \mathrm{m}^{3}$, respectively.

Figure 6 depicts a comparison between experimental and predicted holdup data along with those obtained from the literature references listed in Table 1, and as can be seen the agreement between the predicted and experimental values is within an absolute average relative error of $12 \%$.

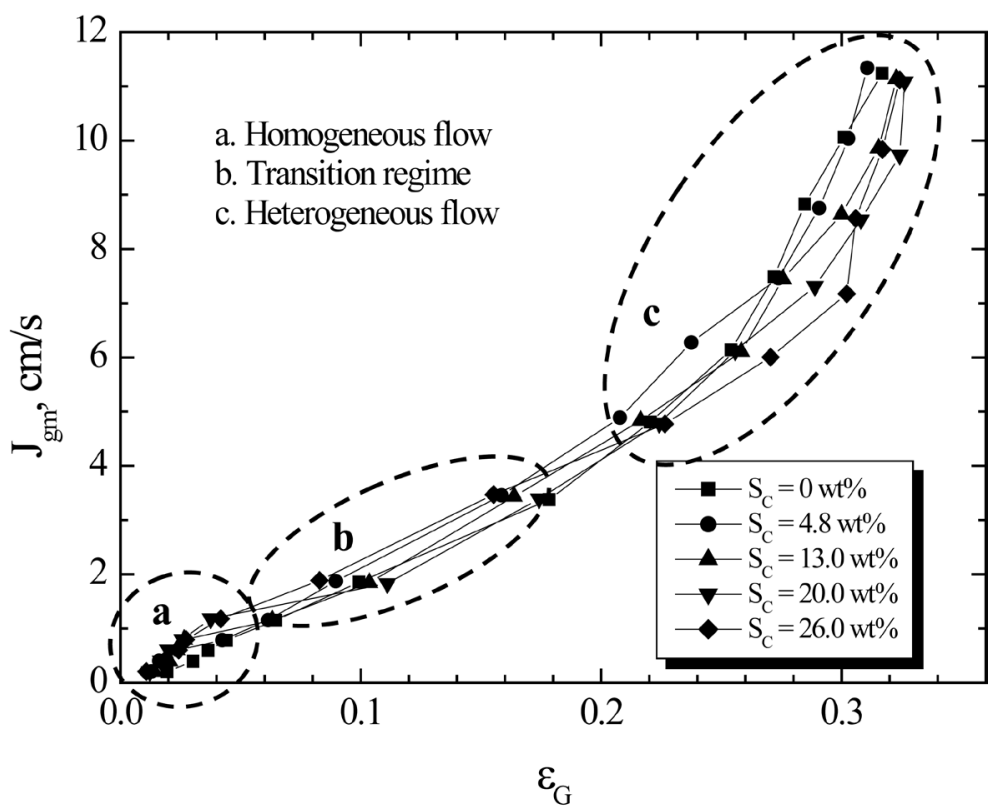

Figure 4. The drift flux plot; volumetric flux of gas phase versus fractional gas holdup in the SBCR with squalane. 


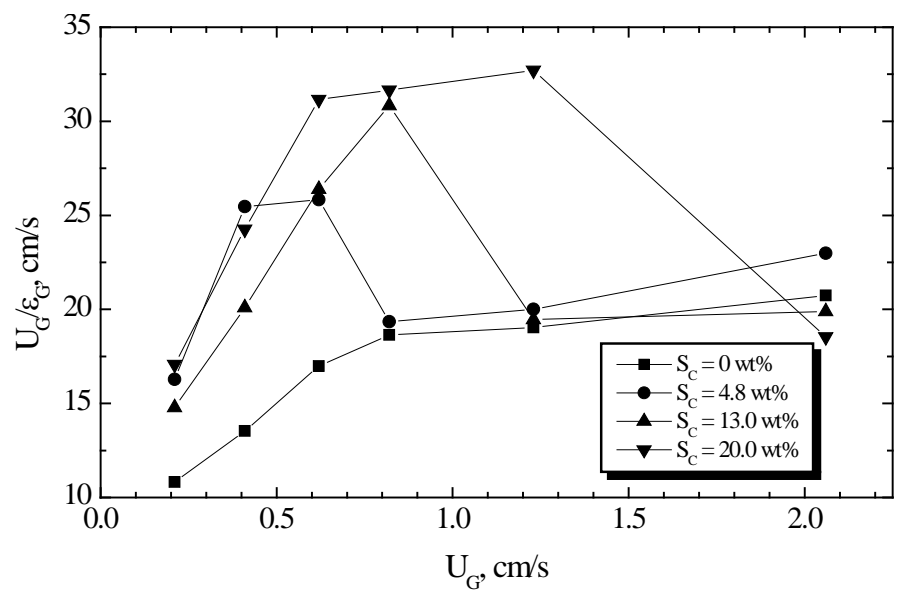

(a) Homogeneous flow regime

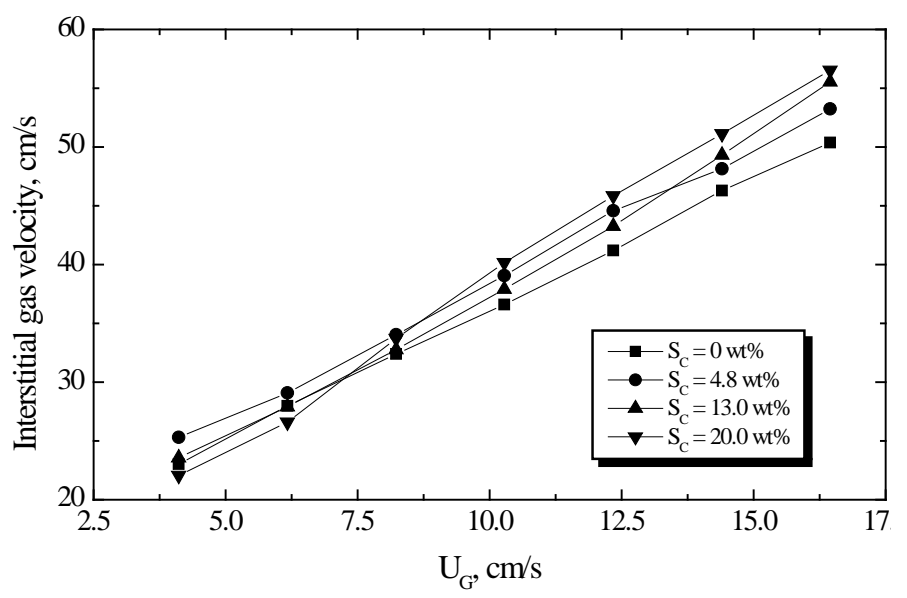

(b) Heterogeneous flow regime

Figure 5. Effect of superficial gas velocity on the local relative velocity at the different flow regime in the SBCR with squalane.

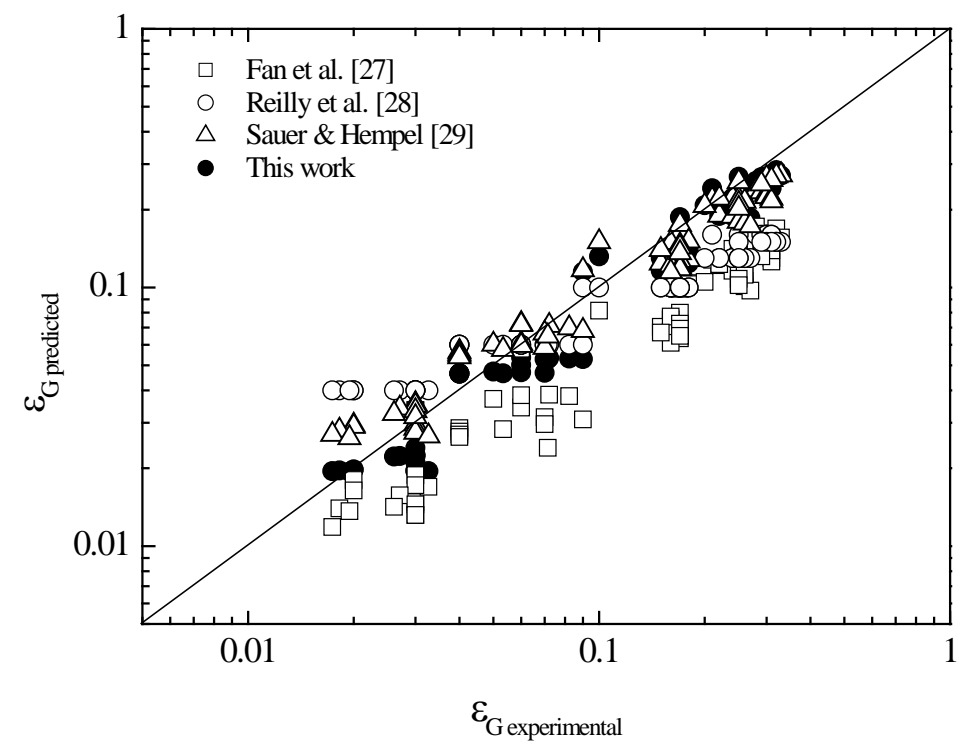

Figure 6. Comparison between predicted and experimental gas holdup data. 
Table 1. Correlation for gas holdup predictions in slurry bubble column reactors.

\begin{tabular}{|c|c|c|c|}
\hline Authors & $\begin{array}{l}\text { Gas/Liquid/ } \\
\text { Solid }\end{array}$ & Conditions & Correlation \\
\hline $\begin{array}{l}\text { Krishna } \\
\text { and Sie [1] }\end{array}$ & $\begin{array}{l}\text { Air/Paraffin oil, } \\
\text { Tellus oil/Silica }\end{array}$ & $\begin{array}{l}P_{a t m} \\
U_{G}: \text { up to } 0.5 \mathrm{~m} / \mathrm{s} \\
C_{V}: 0-36 \mathrm{vol} . \% \\
D_{C}: 0.1,0.19,0.38,0.63 \mathrm{~m}\end{array}$ & $\begin{array}{l}\varepsilon_{G}=\varepsilon_{G-\text { large }}+\varepsilon_{d f}\left(1-\varepsilon_{G \text {-large }}\right) \\
\varepsilon_{G \text {-large }}=\frac{U_{G}-U_{G-d f}}{U_{b-\text { large }}}, U_{b \text {-arge }}=0.71 \sqrt{g d_{b}}(S F)(A F)(D F) \\
S F=1 \text { for } d_{b} / D_{C}<0.125, \quad S F=1.13 \exp \left(-d_{b} / D_{C}\right) \text { for } 0.125<d_{b} / D_{C}<0.6 \\
S F=0.496\left(D_{c} / d_{b}\right)^{0.5} \text { for } d_{b} / D_{C}>0.6 \\
A F=\alpha+\beta\left(U_{G}-U_{G-\text { df }}\right), \quad D F=\sqrt{1.29 / \rho_{G}}, d b=\gamma\left(U_{G}-U_{G-d f}\right)^{\delta} \\
\text { for Tellus oil }\left(\rho_{L}=862, \mu_{L}=0.075, \sigma_{L}=0.028\right) \\
\alpha=2.25, \beta=4.09, \gamma=0.069, \delta=0.376 \\
U_{G-\text {-df }}=U_{b-\text {-small }} \varepsilon_{d f} \\
\varepsilon_{d f}=\varepsilon_{d f, 0}\left(\frac{\rho_{G}}{\rho_{G, \text { ref }}}\right)^{0.48}\left(1-\frac{0.7}{\varepsilon_{d f, 0}} C_{V}\right), \\
\varepsilon_{d f, 0}=0.27 \text { for paraffin oil }\left(\rho_{L}=790, \mu_{L}=0.029, \sigma_{L}=0.028\right)\end{array}$ \\
\hline $\begin{array}{l}\text { Koide } \\
\text { et al. [8] }\end{array}$ & $\begin{array}{l}\mathrm{N}_{2} / \mathrm{H}_{2} \mathrm{O} \text {, } \\
\text { glycerol, glycol, } \\
\text { barium chloride, } \\
\text { sodium } \\
\text { sulphate/Glass } \\
\text { and bronze }\end{array}$ & $\begin{array}{l}P_{a t m} \\
U_{G}: 0.03-0.15 \mathrm{~m} / \mathrm{s} \\
C_{S}: 0-200 \mathrm{~kg} / \mathrm{m}^{3} \\
D_{C}: 0.1-0.3 \mathrm{~m} \\
H_{C}: 2.3-3 \mathrm{~m}\end{array}$ & $\begin{array}{l}\frac{\varepsilon_{G}}{\left(1-\varepsilon_{G}\right)^{4}}=\frac{A\left(U_{G} \mu_{L} / \sigma\right)^{0.918}\left(g \mu_{L}^{4} / \rho_{L} \sigma^{3}\right)^{-0.252}}{1+4.35\left(\frac{C_{S}}{\rho_{P}}\right)^{0.748}\left(\frac{\rho_{P}-\rho_{L}}{\rho_{L}}\right)^{0.881}\left(\frac{D_{C} U_{G} \rho_{L}}{\mu_{L}}\right)^{-0.168}} \\
A=0.227 \mathrm{H}_{2} \mathrm{O} \text {, Glycerol, Glycol } \\
A=0.364 \text { Aqueous solution of inorganic electrolytes }\end{array}$ \\
\hline $\begin{array}{l}\text { Kara } \\
\text { et al. [11] }\end{array}$ & $\begin{array}{l}\text { Air } / \mathrm{H}_{2} \mathrm{O} / \text { Coal, } \\
\text { dried mineral ash }\end{array}$ & $\begin{array}{l}P_{a t m} \\
U_{G}: 0.03-0.3 \mathrm{~m} / \mathrm{s} \\
U_{S L}: 0-0.1 \mathrm{~m} / \mathrm{s} \\
C_{W}: 0-40 \mathrm{wt} . \% \\
D_{C} \times H_{C}: \text { N/A }\end{array}$ & $\begin{array}{l}\varepsilon_{G}=\frac{\operatorname{Re}_{G}}{A+B \operatorname{Re}_{G}+C \operatorname{Re}_{G}+D\left[\frac{\varepsilon_{S}}{\varepsilon_{S}+\varepsilon_{L}}\right]} \\
A, B, C \text { and } D \text { depend on particle sizes }\end{array}$ \\
\hline $\begin{array}{l}\text { Fan } \\
\text { et al. [27] }\end{array}$ & $\begin{array}{l}\mathrm{N}_{2} / \text { Paratherm } \\
\text { NF/alumina }\end{array}$ & $\begin{array}{l}P: 1-56.2 \text { bar } \\
U_{G} \text { up to } 0.45 \mathrm{~m} / \mathrm{s} \\
C_{V}: 8.1,19.1 \text { vol.\% } \\
T: 28^{\circ} \mathrm{C} \text { and } 78^{\circ} \mathrm{C} \\
D_{C}: 0.102 \mathrm{~m} \\
H_{C}: 1.37 \mathrm{~m}\end{array}$ & $\begin{aligned} \frac{\varepsilon_{G}}{1-\varepsilon_{G}} & =\frac{2.9\left(U_{G}^{4} \rho_{G} / \sigma g\right)^{\alpha}\left(\rho_{G} / \rho_{S L}\right)^{\beta}}{\left[\cosh \left(M o_{S L}^{0.054}\right)\right]^{4.1}} \\
M o_{S L} & =g\left(\rho_{S L}-\rho_{G}\right)\left(\zeta \mu_{L}\right)^{4} / \rho_{S L}^{2} \sigma^{3}, \quad \alpha=0.21 M o_{S L}^{0.0079} \text { and } \beta=0.096 M_{S L}^{-0.011} \\
\operatorname{Ln} \zeta= & 4.6 C_{V}\left\{5.7 C_{V}^{0.58} \sinh \left[-0.71 \exp \left(-5.8 C_{V}\right) \ln M o^{0.22}\right]+1\right\}\end{aligned}$ \\
\hline $\begin{array}{l}\text { Reilly et al. } \\
\text { [28] }\end{array}$ & $\begin{array}{l}\text { Air/ } \mathrm{H}_{2} \mathrm{O}, \\
\text { Solvent, TCE/ } \\
\text { Glass beads }\end{array}$ & $\begin{array}{l}P_{a t m} \\
U_{G}: 0.02-0.2 \mathrm{~m} / \mathrm{s} \\
C_{V}: \text { up to } 10 \mathrm{vol} . \% \\
H_{C} \times D_{C}: 5 \times 0.3 \mathrm{~m}\end{array}$ & $\varepsilon_{G}=296 U_{G}^{0.44} \rho_{L}^{-0.98} \sigma_{L}^{-0.16} \rho_{G}^{0.19}+0.009$ \\
\hline $\begin{array}{l}\text { Sauer and } \\
\text { Hempel } \\
\text { [29] }\end{array}$ & $\begin{array}{l}\text { Air } / \mathrm{H}_{2} \mathrm{O} / 10 \text { diff. } \\
\text { Solids } \\
\left(1020<\rho_{P}<\right. \\
\left.2780 \mathrm{~kg} / \mathrm{m}^{3}\right)\end{array}$ & $\begin{array}{l}P_{a t m} \\
U_{G}: 0.01-0.08 \mathrm{~m} / \mathrm{s} \\
C_{V}: 0-20 \mathrm{vol} . \%\end{array}$ & $\begin{array}{l}\frac{\varepsilon_{G}}{1-\varepsilon_{G}}=0.0277\left(\frac{U_{G}}{\left(U_{G} g v_{s l}\right)^{0.25}}\right)^{0.844}\left(\frac{v_{s l}}{v_{\text {eff }, \text { rad }}}\right)^{-0.136}\left(\frac{C_{s}}{C_{s 0}}\right)^{0.0392} \\
\text { where } C_{S 0} \text { is solid concentratrion at bottom of column, } \mathrm{kg} / \mathrm{m}^{3} \\
v_{s l}=\mu_{L}\left[1+2.5 C_{V}+10.05 C_{V}^{2}+0.00273 \exp \left(16.6 C_{V}\right)\right] / \rho_{s l} \\
v_{\text {effrad }}=0.011 D_{C} \sqrt{g D_{C}}\left(\frac{U_{G}^{3}}{g v_{L}}\right)^{1 / 8}\end{array}$ \\
\hline $\begin{array}{l}\text { Schumpe } \\
\text { et al. } \\
\text { [30] }\end{array}$ & $\begin{array}{l}\mathrm{N}_{2}, \mathrm{O}_{2} / \mathrm{H}_{2} \mathrm{O} \\
0.8 \mathrm{M} \\
\mathrm{Na}_{2} \mathrm{SO}_{4} / \text { Carbon, } \\
\text { Kiselguhr, } \\
\text { Aluminum } \\
\text { oxide }\end{array}$ & $\begin{array}{l}P_{a t m} \\
U_{G}: \text { up to } 0.07 \mathrm{~m} / \mathrm{s} \\
C_{S}: \text { up to } 300 \mathrm{~kg} / \mathrm{m}^{3} \\
D_{C}: 0.095 \mathrm{~m} \\
H_{C}: 0.85 \mathrm{~m}\end{array}$ & $\begin{array}{l}\varepsilon_{G}=F U_{G}^{0.87} \mu_{\text {eff }}^{-0.18} \\
F=0.81\left(\mathrm{H}_{2} \mathrm{O} / \text { salt solution) }\right. \\
F=0.43\left(\mathrm{H}_{2} \mathrm{O}, 0.8 \mathrm{M} \mathrm{Na}_{2} \mathrm{SO}_{4}\right) \\
\mu_{\text {eff }}=k\left(2800 U_{G}\right) \\
\text { Where } k \text { is the fluid consistency index (Pa sn) } k=1.97, n=0.951 \text { and } \\
B=0.81 \text { or } 0.43\end{array}$ \\
\hline
\end{tabular}


The heat transfer phenomenon is very important scale-up factor to design the practical SBCR plant. In this work, the local heat transfer coefficient (h) was determined by means of Equation (4) from the knowledge of the mean value of differential temperature between the immersed heat transfer tube and the bed. The effect of superficial gas velocity $\left(U_{G}\right)$ on the local heat transfer coefficient can be seen in Figure 7 . In this figure, the h value increases linearly with increasing $U_{G}$ in all cases of low $U_{G}$. This can be attributed to the increase of turbulence in the SBCR due to the increase of gas holdup and gas momentum flow rate with increasing $U_{G}$ [5] [31]. As a result, the increase of turbulent intensity makes the boundary layer thickness at the surface of heat transfer tube to be thin, giving the high $h$ values [26]. But, the $h$ value in heterogeneous flow up to $10 \mathrm{~cm} / \mathrm{s} \mathrm{can} \mathrm{be} \mathrm{shown}$ to be insignificant. This is because the positive effect by the increase of turbulent intensity cancels out the negative effect by the increase of bubble size with increasing $U_{G}$. In the case of paraffin oil, the $h$ value obtained is generally higher than that of squalane since the large bubbles formed by bubble coalescence in liquid phase of high viscosity.

Effects of the solid concentration on the local heat transfer coefficient can be seen in Figure 8. In this figure, the $\mathrm{h}$ value decreases slowly with increasing solid concentration. This can be attributed to an increase in apparent slurry viscosity and corresponding increase in average boundary layer thickness at the tube surface for heat

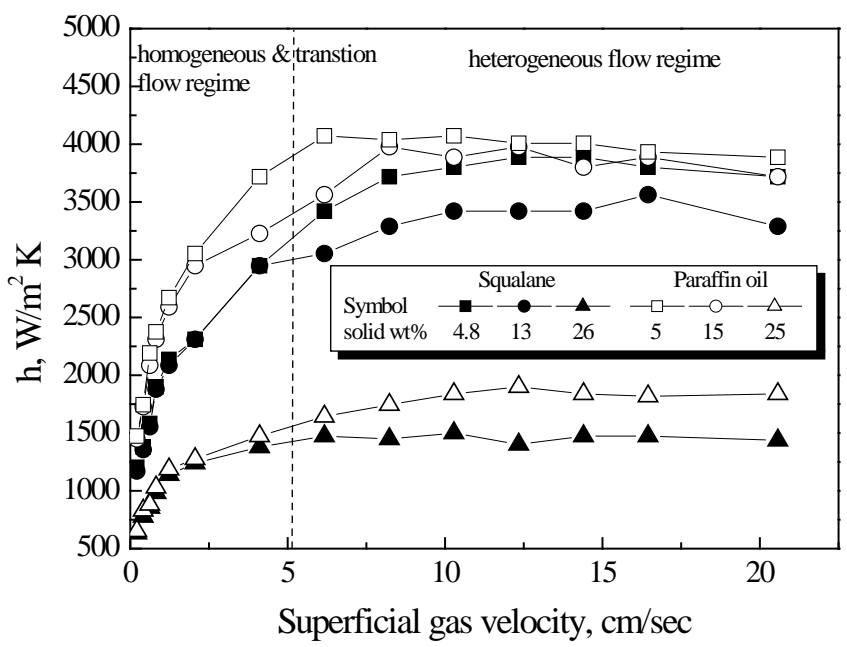

Figure 7. Effects of superficial gas velocity on the local heat transfer coefficient (h) in a slurry bubble column reactor.

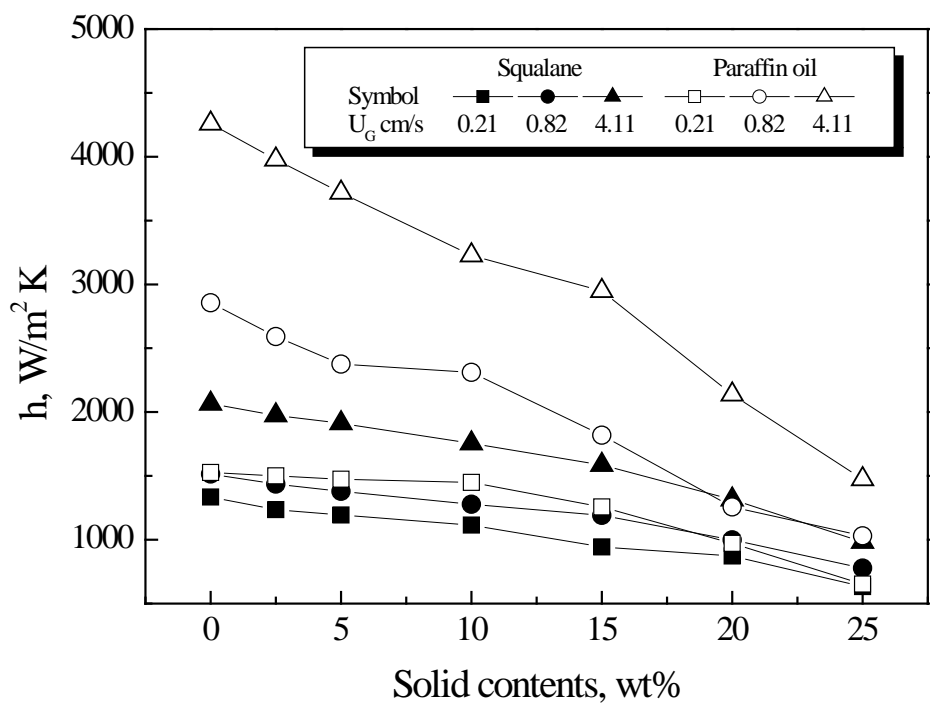

Figure 8. Effects of solid concentration on the local heat transfer coefficient (h) in a slurry bubble column reactor. 
transfer, with increasing slurry concentration [6]. In other words, the residence time of bubbles in the column decreases owing to the increase of rising velocity of bubbles. This reduces the bubble holdup considerably in the column. Moreover, the size distribution of bubbles becomes wider with the increasing bubble size, which can lead to the generation of the more irregular bubbling phenomena [26].

In general, the heat transfer coefficient by several investigators in three-phase fluidized beds has been correlated in terms of the experimental variables such as gas and liquid velocities, particle size and liquid viscosity. Also, semi-theoretical correlations have been proposed based on the energy dissipation rate to predict $h$ in threephase fluidized beds [32]. However, for the design and scale-up of multi-phase flow reactors such as three-phase fluidized bed, inverse fluidized bed or SBCR, it is desirable to predict h from the dimensionless correlations. Thus, in this paper, we proposed the modified correlations by dimensionless groups such as Nusselt number, Reynolds number and Prandtl number as Equation (6).

$$
\begin{aligned}
& \mathrm{Nu}=f(\mathrm{Re}, \mathrm{Pr}, \cdots) \\
& \mathrm{Nu}=\frac{h d_{p}\left(1-\varepsilon_{S L}\right)}{k_{L} \varepsilon_{S L}}, \quad \operatorname{Re}=\frac{d_{p} \rho_{L} U_{G}}{\mu_{L} \varepsilon_{S L}}, \quad \operatorname{Pr}=\frac{C_{P L} \mu_{L}}{k_{L}}
\end{aligned}
$$

Local heat transfer coefficients between the immersed heater and the bed in the given experimental conditions have been well correlated in terms of dimensionless groups. The following correlations are obtained for the homogeneous and in the heterogeneous flow, respectively as shown in Equations (7) \& (8).

$$
\begin{aligned}
& N u=\frac{h d_{p}\left(1-\varepsilon_{S L}\right)}{k_{L} \varepsilon_{S L}}=1.86 \times 10^{-3}\left(\frac{d_{p} \rho_{L} U_{G}}{\mu_{L} \varepsilon_{S L}}\right)^{1.024}\left(\frac{C_{P L} \mu_{L}}{k_{L}}\right)^{2.487} \\
& N u=\frac{h d_{p}\left(1-\varepsilon_{S L}\right)}{k_{L} \varepsilon_{S L}}=3.12 \times 10^{-3}\left(\frac{d_{p} \rho_{L} U_{G}}{\mu_{L} \varepsilon_{S L}}\right)^{0.522}\left(\frac{C_{P L} \mu_{L}}{k_{L}}\right)^{2.260}
\end{aligned}
$$

where, $\varepsilon_{S L}$ is the slurry phase holdup and the Equations (7) \& (8) have fitted well with the experimentally obtained heat transfer coefficient with a correlation coefficient of 0.92 and 0.96 , respectively. In addition, we compared with the results of references on the heat transfer coefficient. The heat transfer coefficient and the operation conditions correlated in terms of operating variable can be written dimensionless,

$$
\mathrm{St}=C\left(\operatorname{ReFr} \operatorname{Pr}^{2}\right)^{-1 / 4}
$$

Figure 9 represents the Stanton number $\left(h / C_{p} \rho U_{G}\right)$ plotted against the dimensionless group $(\operatorname{ReFrPr})^{-1 / 4}$ for various slurry systems which is described in more detailed in Table 2. As expected, Equation (9) fits just as well as it dose reference's data [20] [25] [32] [33] and our data, producing a figure of $C=0.1$ for heat transfer.

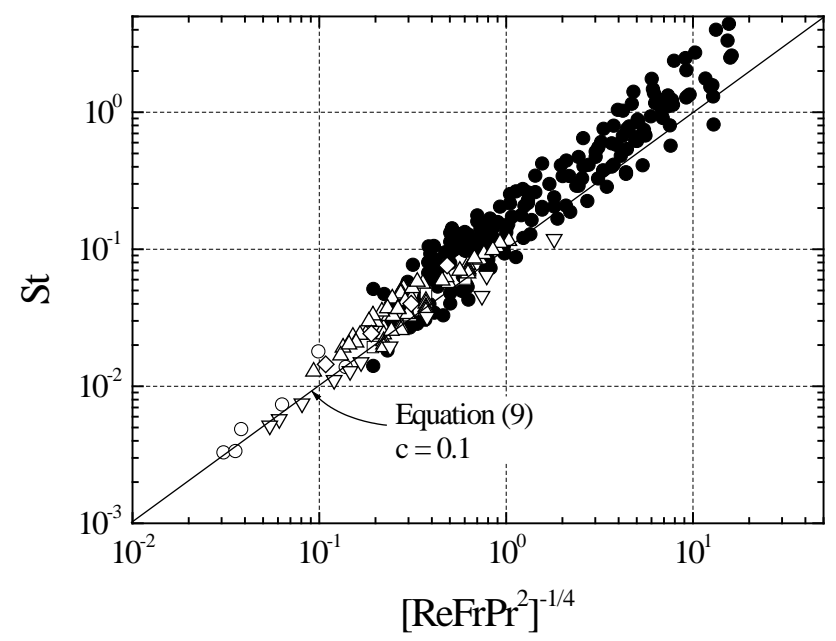

Figure 9. Correlation of heat transfer coefficient measured in slurry phase based on Equation (9) (material systems and symbols given in Table 2). 
Table 2. Slurry systems used to check the validity of Equation (9), see Figure 9.

\begin{tabular}{cccccc}
\hline Author & Solid Phase & Solid Content $(\mathrm{wt} \%)$ & Temperature $\left({ }^{\circ} \mathrm{C}\right)$ & Viscosity $(\mathrm{mPa} \cdot \mathrm{s})$ & Symbol in Figure 9 \\
\hline Deckwer et al. [21] & Paraffin- $\mathrm{Al}_{2} \mathrm{O}_{3}$ & $5.5-16.0$ & 220 & $4.3-4.8$ & $\square$ \\
& & $5.5-16.0$ & 260 & $2.1-2.3$ & 0 \\
Kang et al. [26] & CMC Sol'n-silica gel & $0-20$ & 25 & $0.96-38$ & $\checkmark$ \\
Müller [33] & Water-kieselguhr & 18.0 & $20-26$ & 99 & $\checkmark$ \\
Deckwer [34] & Water-sand & & & 1.4 & $\bullet$ \\
This work & $40 \mu \mathrm{m}$ & 20.0 & 25 & $16.9,25.9$ & $\bullet$
\end{tabular}

\section{Conclusion}

From the results of this investigation on the gas holdup and the heat transfer in a slurry bubble column reactor, we can obtain the following conclusions. The gas holdup in a slurry bubble column reactor increases with increasing $U_{G}$, but it decreases with increasing $S_{C}$ or slurry viscosity because of the formation of large bubbles and the faster rising velocity of bubble, apart from transition from homogenous to churn turbulent flow regime. Moreover, the flow regimes can be distinguished by a modified drift flux model which takes into consideration the relationship between gas holdup and superficial gas velocity. The non-uniformity of bubble holdup can be estimated by a distribution parameter $(K)$ in the heterogeneous flow regime. The local heat transfer coefficient between the immersed heater and the bed increases with increasing $U_{G}$. On the contrary, it decreases with $S_{C}$ or viscosity of slurry phase because the boundary layer thickness at the surface of heat transfer tube becomes thick. Finally, under the experimental conditions studied, good correlations are obtained to predict the local heat transfer coefficient between the immersed heater and bed in terms of dimensionless groups for different flow regimes.

\section{Acknowledgments}

This subject is supported by Korea Ministry of Environment as "Program for promoting commercialization of promising environmental technologies”.

\section{References}

[1] Krishna, R. and Sie, S.T. (2000) Design and Scale-Up of the Fischer-ropsch Bubble Column Slurry Reactor. Fuel Processing Technology, 64, 73. http://dx.doi.org/10.1016/S0378-3820(99)00128-9

[2] Zhang, K., Song, H.S. and Sun, D.K. (2003) Low-Temperature Methanol Synthesis in a Circulating Slurry Bubble Reactor. Fuel, 82, 233. http://dx.doi.org/10.1016/S0016-2361(02)00221-1

[3] Clerici, G.C.E. and Belmonte, G. (2006) Hydrocarbons from Synthesis Gas in Slurry Reactors and for the Separation of the Liquid Phase Produced from the Solid Phase. US Patent 7,144,924.

[4] Inga, J.R. and Morsi, B.I. (1999) Effect of Operating Variables on the Gas Holdup in a Large-Scale Slurry Bubble Column Reactor Operating with an Organic Liquid Mixture. Industrial Engineering Chemistry Research, 38, 928. http://dx.doi.org/10.1021/ie980384q

[5] Yang, G.Q., Luo, X., Lau, R. and Fan, L.S. (2000) Heat-Transfer Characteristics in Slurry Bubble Columns at Elevated Pressures and Temperatures. Industrial Engineering Chemistry Research, 39, 2568. http://dx.doi.org/10.1021/ie990774s

[6] Li, H., Prakash, A., Margaritis, A. and Bergougnou, M.A. (2003) Effects of Micron-Sized Particles on Hydrodynamics and Local Heat Transfer in a Slurry Bubble Column. Powder Technology, 133, 171. http://dx.doi.org/10.1016/S0032-5910(03)00118-9

[7] Deckwer, W.D. (1992) Bubble Column Reactors. Wiley, Chichester, 399.

[8] Koide, K., Takazawa, A., Komura, M. and Matsunaga, H. (1984) Gas Holdup and Volumetric Liquid-Phase Mass Transfer Coefficient in Solid-Suspended Bubble Columns. Journal of Chemical Engineering of Japan, 17, 459. http://dx.doi.org/10.1252/jcej.17.459

[9] Saxena, S.C., Rao, N.S. and Saxena, A.C. (1990) Heat-Transfer and Gas-Holdup Studies in a Bubble Column: AirWater-Glass Bead System. Chemical Engineering Communications, 96, 31. 
http://dx.doi.org/10.1080/00986449008911481

[10] Fan, L.S. (1989) Gas-Liquid-Solid Fluidization Engineering. Butterworths, Boston.

[11] Kara, S., Kelkar, B.G., Shah, Y.T. and Carr, N.L. (1982) Hydrodynamics and Axial Mixing in a Three-Phase Bubble Column. Industrial \& Engineering Chemistry Process Design and Development, 21, 584-594. http://dx.doi.org/10.1021/i200019a009

[12] Wallis, G.B. (1969) One-Dimensional Two-Phase Flow. McGraw-Hill, New York, 243.

[13] Thorat, B.N. and Joshi, J.B. (2004) Regime Transition in Bubble Columns: Experimental and Predictions. Experimental Thermal and Fluid Science, 28, 423-430. http://dx.doi.org/10.1016/j.expthermflusci.2003.06.002

[14] Zuber, N. and Findlay, J.A. (1965) Average Volumetric Concentration in Two-Phase Flow Systems. Journal of Heat Transfer, 87, 453-468. http://dx.doi.org/10.1115/1.3689137

[15] Xie, T., Ghiaasiaan, S.M., Karrila, S. and McDonough, T. (2003) Flow Regimes and Gas Holdup in Paper Pulp-WaterGas Three-Phase Slurry Flow. Chemical Engineering Science, 58, 1417-1430. http://dx.doi.org/10.1016/S0009-2509(02)00660-7

[16] Ruzicka, M.C., Zahradnik, J., Drahos, J. and Thomas, N.H. (2001) Homogeneous-Heterogeneous Regime Transition in Bubble Columns. Chemical Engineering Science, 56, 4609-4626. http://dx.doi.org/10.1016/S0009-2509(01)00116-6

[17] Tang, C.Z. and Heindel, T.J. (2006) A Gas Holdup Model for Cocurrent Air-Water-Fiber Bubble Columns. Chemical Engineering Science, 61, 3299-3312. http://dx.doi.org/10.1016/j.ces.2005.12.011

[18] Hol, P.D. and Heindel, T.J. (2005) Local Gas Holdup Variation in a Fiber Slurry. Industrial Engineering Chemistry Research, 44, 4778-4784. http://dx.doi.org/10.1021/ie050041+

[19] Cho, Y.J., Song, P.S., Kim, S.H., Kang, Y. and Kim, S.D. (2001) Journal of Chemical Engineering of Japan, 34, 254261. http://dx.doi.org/10.1252/jcej.34.254

[20] Drahos, J., Zahradnik, J., Bradka, F. and Puncochar, M. (1992) Fractal Behaviour of Pressure Fluctuations in a Bubble Column. Chemical Engineering Science, 47, 4069-4075. http://dx.doi.org/10.1016/0009-2509(92)85158-8

[21] Deckwer, W.D., Louisi, Y., Zaidi, A. and Ralek, M. (1980) Hydrodynamic Properties of the Fischer-Tropsch Slurry Process. Industrial \& Engineering Chemistry Process Design and Development, 19, 699-708. http://dx.doi.org/10.1021/i260076a032

[22] Shah, Y.T., Kelkar, B.G., Godbole, S.P. and Deckwer, W.D. (1982) Design Parameters Estimations for Bubble Column Reactors. AIChE Journal, 28, 353-379. http://dx.doi.org/10.1002/aic.690280302

[23] Crabtree, J.R. and Bridgwater, J. (1971) Bubble Coalescence in Viscous Liquids. Chemical Engineering Science, 26, 839-851. http://dx.doi.org/10.1016/0009-2509(71)83045-2

[24] Bakshi, B.R., Zhong, H., Jiang, P. and Fan, L.-S. (1996) Analysis of Flow in Gas-Liquid Bubble Columns Using Multi-Resolution Methods. Transactions of the American Institute of Chemical Engineers, 73, 608-614.

[25] Letzel, H.M., Schouten, J.C., Krishna, R. and Van den Bleek, C.M. (1997) Characterization of Regimes and Regime Transitions in Bubble Columns by Chaos Analysis of Pressure Signals. Chemical Engineering Science, 52, 4447-4459. http://dx.doi.org/10.1016/S0009-2509(97)00290-X

[26] Kang, S.H., Son, S.M., Kang, Y., Bae, J.W. and Jun, K.W. (2008) Effects of Pressure Fluctuations on the Heat Transfer Characteristics in a Pressurized Slurry Bubble Column. Korean Journal of Chemical Engineering, 25, 897-904. http://dx.doi.org/10.1007/s11814-008-0148-5

[27] Fan, L.S., Yang, G.Q., Lee, D.J., Tsuchiya, K. and Luo, X. (1999) Some Aspects of High-Pressure Phenomena of Bubbles in Liquids and Liquid-Solid Suspensions. Chemical Engineering Science, 54, 4681-4709. http://dx.doi.org/10.1016/S0009-2509(99)00348-6

[28] Reilly, I.G., Scott, D.S., de Bruijn, T.J.W., Jain, A. and Piskorz, J. (1986) A Correlation for Gas Holdup in Turbulent Coalescing Bubble Columns. The Canadian Journal of Chemical Engineering, 64, 705-717. http://dx.doi.org/10.1002/cjce.5450640501

[29] Sauer, T. and Hempel, D.C. (1987) Fluid Dynamics and Mass Transfer in a Bubble Column with Suspended Particles. Chemical Engineering \& Technology, 10, 180-189. http://dx.doi.org/10.1002/ceat.270100123

[30] Schumpe, A., Saxena, A.K. and Fang, L.K. (1987) Gas/Liquid Mass Transfer in a Slurry Bubble Column. Chemical Engineering Science, 42, 1787-1796. http://dx.doi.org/10.1016/0009-2509(87)80183-5

[31] Lin, T.J. and Fan, L.S. (1999) Heat Transfer and Bubble Characteristics from a Nozzle in High-Pressure Bubble Columns. Chemical Engineering Science, 54, 4853-4859. http://dx.doi.org/10.1016/S0009-2509(99)00205-5

[32] Kim, S.D. and Kang, Y. (1997) Heat and Mass Transfer in Three-Phase Fluidized-Bed Reactors-An Overview. Chemical Engineering Science, 52, 3639-3660. http://dx.doi.org/10.1016/S0009-2509(97)00269-8

[33] Müller, K. (1958) Heat Transfer in Viscous Suspensions in Bubble Columns. Dissertation, Technical University of Berlin, Berlin. 
[34] Deckwer, W.D. (1992) Bubble Column Reactors. Wiley, Chichester, 270.

\section{Nomenclature}

$A$ : heater outside area $\left(\mathrm{m}^{2}\right)$

$C_{P L}$ : heat capacity of liquid $(\mathrm{J} / \mathrm{kg} \mathrm{K})$

$d_{P}$ : mean particle size $(\mathrm{m})$

$h$ : individual heat transfer coefficient $\left(\mathrm{W} / \mathrm{m}^{2} \mathrm{~K}\right)$

$J_{g m}:$ drift flux velocity $(\mathrm{m} / \mathrm{s})$

$K$ : degree of non-uniformity in the radial direction

$k_{L}$ : thermal conductivity of liquid (W/m K)

$S_{C}$ : solid concentration (wt $\%$ )

$T_{b}$ : bed temperature (K)

$T_{S}$ : heater surface temperature $(\mathrm{K})$

$U_{L}$ : superficial liquid velocity $(\mathrm{m} / \mathrm{s})$

$U_{G}$ : superficial gas velocity $(\mathrm{m} / \mathrm{s})$

$\bar{V}_{g m}$ : weighted mean drift velocity $(\mathrm{m} / \mathrm{s})$

Vs: local slip velocity $(\mathrm{m} / \mathrm{s})$

\section{Greek Letters}

$\rho_{L}$ : liquid density $\left(\mathrm{kg} / \mathrm{m}^{3}\right)$

$\mu_{L}$ : liquid viscosity (Pa.s)

$\varepsilon_{G}:$ gas holdup

$\varepsilon_{L}$ : liquid holdup

$\varepsilon_{S}$ : solid holdup

$\varepsilon_{S L}$ : slurry phase holdup 
Scientific Research Publishing (SCIRP) is one of the largest Open Access journal publishers. It is currently publishing more than 200 open access, online, peer-reviewed journals covering a wide range of academic disciplines. SCIRP serves the worldwide academic communities and contributes to the progress and application of science with its publication.

Other selected journals from SCIRP are listed as below. Submit your manuscript to us via either submit@scirp.org or Online Submission Portal.
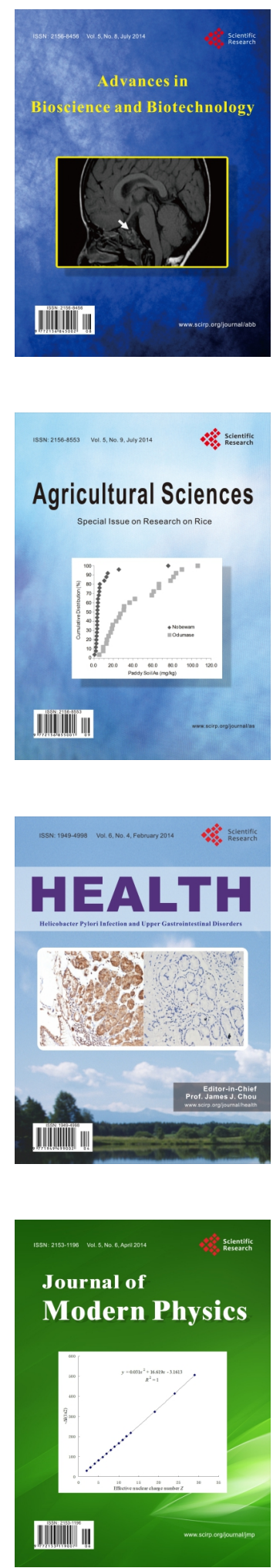
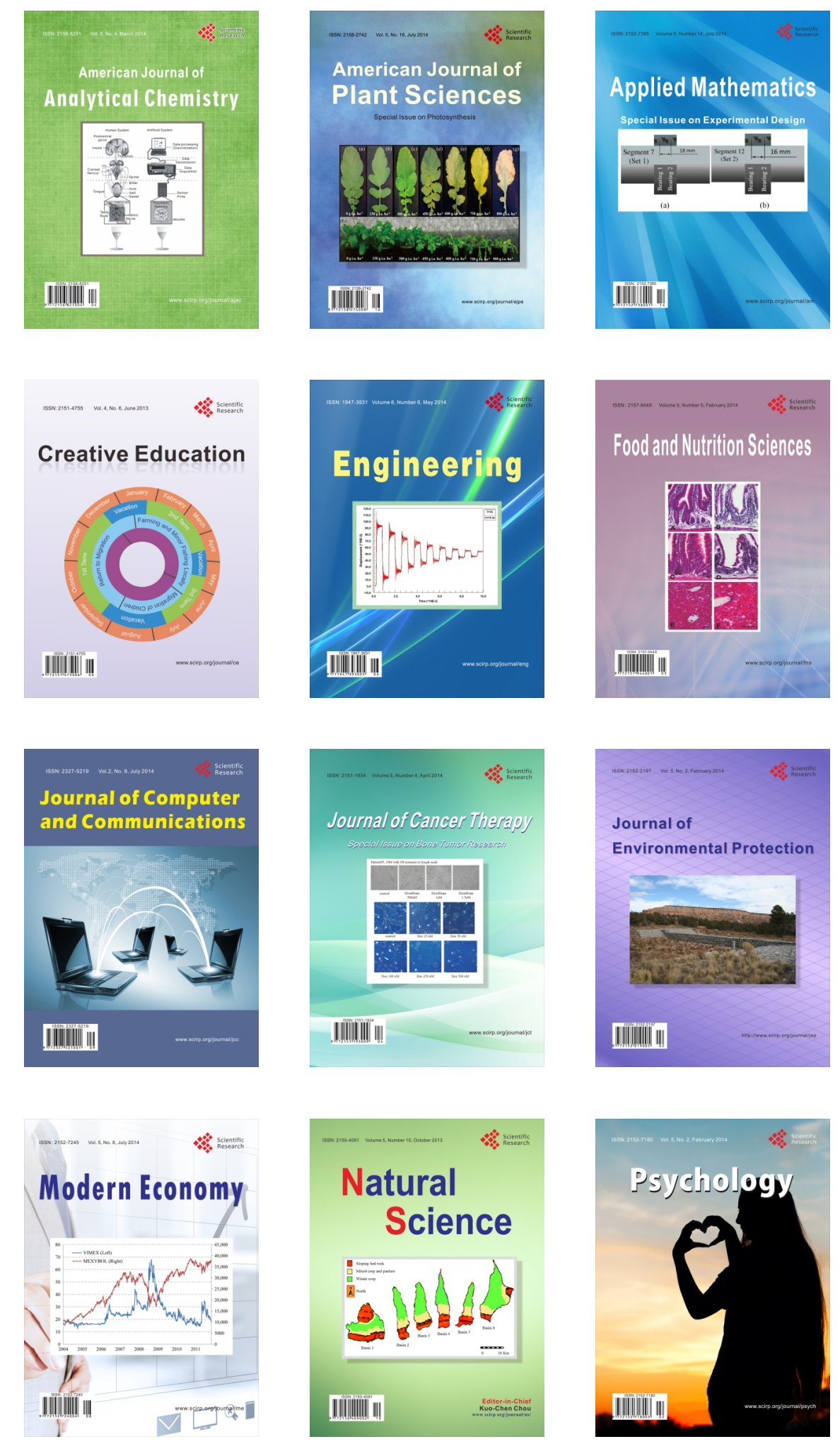